\title{
ENHANCING TERRITORIAL CAPITAL FOR DEVELOPING MOUNTAIN AREAS: THE EXAMPLE OF TRENTINO AND ITS USE OF MEDICINAL AND AROMATIC PLANTS
}

Federico Bigaran, Astrid Mazzola, Adriana Stefani

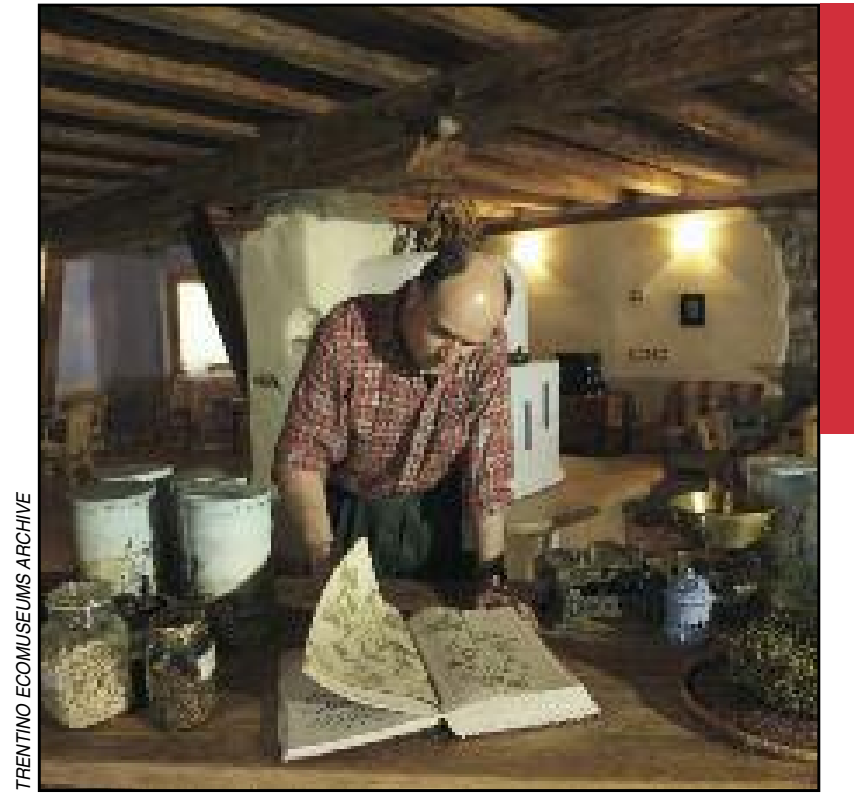

The knowledge of using medicinal and aromatic plants represents the culture of rural areas and can foster a better interaction between local farms and the tourism sector. (photograph: Trentino Ecomuseums archive). 


\title{
Enhancing territorial capital for developing mountain areas: the example of Trentino and its use of medicinal and aromatic plants
}

DOI: $10.3986 /$ AGS53403

UDC: 711.1(450.32)

502.131.1:633.81(450.32)

COBISS: 1.01

\begin{abstract}
:
Today mountain areas are facing major economic challenges, due to depopulation, a lack of competitiveness and the impact of climate change. To combat this trend, it has been surmised that an integrated development approach based on innovation, cooperation between the public and private sectors and enhancement of the local cultural heritage could create new opportunities. The authors will report on SY_CULTour pilot project initiatives promoted by the Autonomous Province of Trento in cooperation with the Trentino Ecomuseums Network to promote the exploitation of medicinal and aromatic plants, using an integrated approach. A description of the starting up of the pilot project and interviews with those cultivating medicinal plants will be used to highlight innovative processes underway in the ecomuseum areas, in an attempt to show how the cultural heritage, landscape and environment could be integrated to encourage the economic development of mountain communities, as a strategic factor in sustainable development.
\end{abstract}

KEY WORDS: geography, sustainable development, medicinal plants, mountain areas, integrated approach, SY_CULTour, territorial capital, rural tourism, cultural values

The article was submitted for publication on December 20, 2012.

\section{ADDRESSES:}

Federico Bigaran, Ph. D.

Autonomous Province of Trento

Organic Production Office

Via G. B. Trener 3, IT - 38121 Trento, Italy

E-mail: federico.bigaran@provincia.tn.it

\section{Astrid Mazzola}

Autonomous Province of Trento

Organic Production Office

Via G. B. Trener 3, IT - 38121 Trento, Italy

E-mail: astrid.mazzola@provincia.tn.it

\section{Adriana Stefani}

Trentino Ecomuseums Network secretariat

C/o Vanoi Ecomuseum

Piazza V. Emanuele, IT - 38050 Canal San Bovo, Italy

E-mail: info@ecomusei.trentino.it 


\section{Contents}

1 Introduction 382

$2 \quad$ Integrated development in the Alps 382

2.1 The Alps: from self-sufficiency to marginality 382

2.2 Integrated development as a strategy for revitalising mountain areas $\quad 382$

2.3 Medicinal plants in the context of integrated development $\quad 383$

3 Methods 383

$4 \quad$ Project background: Trentino and the

4.1 The SY_CULTour project in Trentino 385

4.2 Trentino and its ecomuseums 386

5 Ecomuseums, farmers and local systems 386

5.1 The SY_CULTour project implementation and the local territorial systems approach 386

5.2 Seven pilot actions, one project 386

5.3 Farmers and local systems 388

6 Conclusions 390

7 References 391 


\section{Introduction}

The development of mountain areas has traditionally been based on the sustainable use of local resources. However, this development has recently experienced a crisis, as a consequence of the dynamics of modernisation, which have led to the loss of many services traditionally present and to extensive migration of the population from rural to urban areas, thus leading to the decline of rural mountain economies.

To combat this decline, which places the cultural and environmental richness of mountain areas at risk, it would seem necessary to adopt sustainable and integrated development strategies, designed to introduce innovation while respecting, indeed enhancing, what already exists.

This paper describes the initial phases of the pilot project »From tradition to production. The sustainable use of cultivated and spontaneous medicinal plants in the context of rural tourism « drawn up in the context of the European Community project SY_CULTour - Synergy between culture and tourism: the use of cultural potentials in less favoured rural regions (http://www.sycultour.eu), referring to the Interreg SEE programme.

In the territory of the Province of Trento, it was decided to base a series of small initiatives in the areas of the seven Trentino ecomuseums on medicinal and aromatic plants. The role of the ecomuseums, which focuses on recovery of the local culture, was to promote the cultural heritage linked to Medicinal and Aromatic Plants (MAP) and create opportunities for tourism. Each action was developed by attempting to involve all the potential local stakeholders, adopting a participatory method in order to fully exploit widespread knowledge and skills.

\section{Integrated development in the Alps}

\subsection{The Alps: from self-sufficiency to marginality}

The history of the Alps demonstrates the existence of a model of development based on self-sufficiency and sustainability. However, today mountain areas have a marginal role and are subject to a development model drawn up elsewhere, incapable of exploiting their specific characteristics and which on the contrary often increases their fragility (for a bibliography, see Mazzola 2011).

Mountain areas today therefore suffer from numerous problems, mostly linked to the scarcity of services - which leads to depopulation, an ageing population and the abandoning of areas - and innovative business enterprises capable of exploiting their specific nature, transforming this once again into a resource. (Bole and Nared 2009; Euromontana 2011; see also the communications of the European Commission on the subject, 2003, 2004, 2007 and 2011)

The environmental and cultural wealth of these areas is nevertheless considerable, the result of a long history of coexistence and complementarity between man and mountain ecosystems.

\subsection{Integrated development as a strategy for revitalising mountain areas}

The revitalisation of mountain areas, given their complexity and fragility, must necessarily involve a strategy of integrated development, which by adopting an innovative approach (see the 7th European Mountain Convention proceedings 2010) encourages collaboration between the public and private sectors and the enhancement of local resources.

The SLoT (Sistemi Locali Territoriali or Local Territorial Systems) approach, which describes the territory as the system of resources, players and relations existing between the various elements making it up (Corrado 2007; Dematteis and Governa 2005), falls within this context.

According to this approach, a territory is not delimited by administrative or "physical« frontiers (such as rivers or mountains), but is rather defined and continually redefined by systems of relations existing between active players, capable through their joint action of bringing the resources of this area to the fore, creating an entity (the so-called "pertinent area«) with a specific identity, different from any other.

In recent years the alpine area has on several occasions shown itself to be capable of identifying common development strategies. One example is the Alpine Convention, which focuses on integrated sustainable development of the Alps (see http://www.alpconv.org). For the purposes of sustainable development of 
the alpine regions, it is believed to be important to develop both local dynamics (understood as the rediscovery of the area and incentives for the creation of SloTs) and simultaneously »openness «: openness towards other alpine regions, but also to regions outside the Alps and to the world as a whole. Alpine regions should be capable of interacting with the outside world, while at the same time maintaining, indeed reinforcing, their own identity.

\subsection{Medicinal plants in the context of integrated development}

Medicinal and aromatic plants represent one of the topics around which it would be possible to concentrate a strategy for integrated local development of mountain areas, as highlighted in the FairWild Standard (FairWild 2010).

First of all, the virtues of spontaneous plants are the basis of a vast heritage of popular knowledge and beliefs, mostly handed down orally, testifying to the vitality of the relationship between man and mountain ecosystems. The recovery and preservation of this knowledge, today often conserved in particular by elderly people in the villages, represent not only a way of preserving and reinforcing the identity of local communities, often suffering from a considerable loss of memory due to depopulation, but also a possible strategy for creating and characterising tourist destinations.

Secondly, the cultivation of medicinal and aromatic plants can become, and in some cases already is, a business activity capable of stimulating economies suffering from a chronic lack of innovation and investment. The more than thirty members registering with the Trentino trademark Trentinerbe, for whom the production of medicinal and aromatic plants represents a valid source of subsistence or supplementary income, are an illustration of this.

The importance of medicinal and aromatic plants in the context of developing marginal areas is linked not only to the direct sale of products and other products made using them, but also and above all by the networking of producers, restaurants and tourist facilities (farm guest houses and wellness centres in particular) with the objective of creating a wide-ranging tourist proposal directed at a specific target group, namely ecological and cultural tourists.

\section{Methods}

To study local territorial systems and interact with them, in this paper the so-called territorial capital approach is considered to be appropriate. In the last few decades the study of local development has increasingly been oriented towards a cognitive approach centred more on offer than on demand.

An increasingly globalized context, in which the areas which stand out and emerge are those capable of showing the external world their own specific identity and conserving it over time, has led to studies and institutions concentrating on the "added value " of such places. This enables them to attract resources despite the high level of competition in the international context. What has been noted when studying the development of certain »districts « or regions capable of development is that it is not only and not so much material resources that contribute towards this competitiveness, so much as immaterial resources: the shared culture and existing relations but also the ability of stakeholders in those areas to create new relations and introduce innovation. Even more importantly, material and immaterial resources, in what have been called Local Territorial Systems, are part of a complex system of interaction, which ensures that material resources are effectively mobilised precisely through the relations established, and at the same time contribute towards the creation and maintaining of such relations (Camagni 2007).

The concept of »territorial capital « appears for the first time outside the strictly scientific context: proposed by the OECD (Organisation for Economic Co-operation and Development) in the document Territorial Outlook from 2001, and recently recovered by DG Regional Policy of the European Commission, it has soon become part of the scientific debate. The European Commission describes it as follows: Each Region has a specific 'territorial capital' that is distinct from that of other areas and generates a higher return for specific kinds of investments than for others, since these are better suited to the area and use its assets and potential more effectively. Territorial development policies (policies with a territorial approach to development) should first and foremost help areas to develop their territorial capital (quoted in Camagni 2007). 
Figure 1: Territorial capital as the result of the interaction of different components.

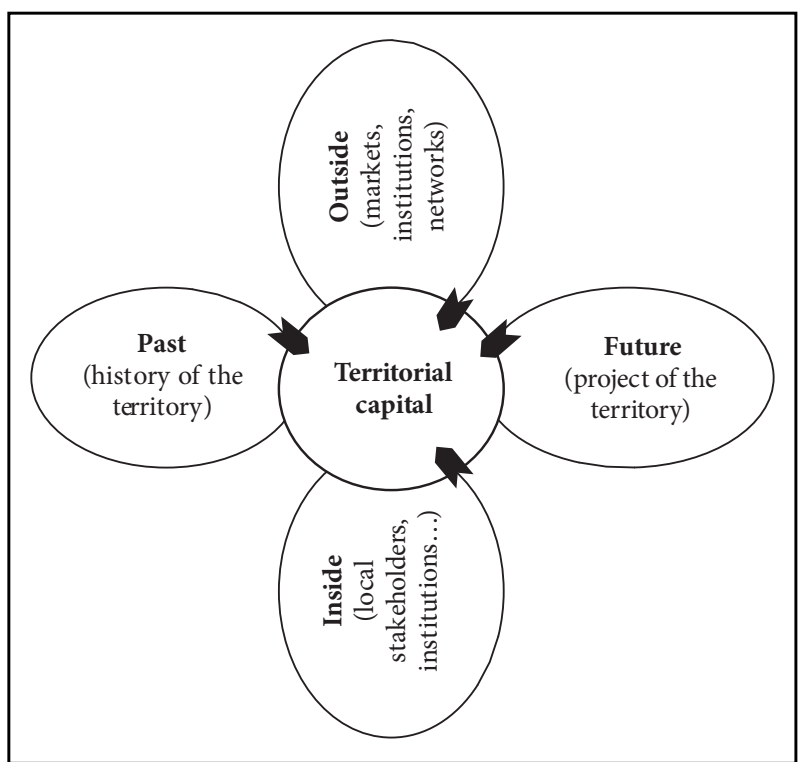

In Italy the concept was picked up on by Camagni, who highlighted that the traditional approach to local development, a functional one, has been progressively replaced by a cognitive approach, where to the cause-effect interpretation of relationships is substituting a more complex vision, focused on the way the economic actors perceive the economic reality: "Local competitivity is interpreted as residing in local trust and a sense of belonging rather than in pure availability of capital; in creativity rather than in the pure presence of skilled labour; in connectivity and relationality more than in pure accessibility; in local identity besides local efficiency and quality of life« (Camagni 2007).

Cultural capital includes everything is considered as »culture«: values, knowledge, rules, ideas, attitudes and behaviours; social capital consists in the relationships between individuals and social groups by means of networking, by which both culture and sociality are created, economic capital includes the wealth produced and collected by means of the individual and social relationships.

Territorial capital is a combination of tangible and intangible elements available in a specific territory, which interweave and are integrated, forming a united and dynamic set of resources. Territorial capital can be considered as a new category of capital rising by the already known other forms of capital in interaction with natural resources (soil, water, climate ...), landscape (which provides ecosystem services, as plant and animal biomass production, soil formation and retention, pollination, climatic regulation, protection against natural hazards) and a localized entity of common assets, that offer collective benefits. The territorial capital components have three combined characteristics: the immobility (they are not transferable), the specificity (they have specific qualities and characteristics that can scarcely be found elsewhere) and the heritage asset (they arise on the territory in the long period and it isn't possible to create them in a short time).

The territorial capital concept is a dynamic one, and is strictly linked to the notion of »territorial planning «: to be competitive, and to attract both economic and human resources, each territory needs to find and enhance its own specificity, creating a unique »image « by which it interacts with external territories and resources (see Dematteis and Governa 2005; Corrado 2007).

Adopting the concept of territorial capital to study an area and to plan actions involving it means therefore bearing in mind a large number of tangible and intangible elements, including local skills and knowledge, networks of knowledge and collective and individual skills, but also the landscape, understood as a social construction deriving from the joint action of the human community and natural forces (as well expressed in the European Landscape Convention adopted in 2000). 
When planning local initiatives designed to enhance territorial capital, a fundamental role is therefore played by the participatory approach, which considers knowledge and skills as an asset divided between local players, which must be mobilised in order for the real potential of an area to emerge.

The territorial capital approach is particularly suitable for studying alpine areas. These are characterised by an extremely rich cultural heritage, whose importance in the context of development has only recently been rediscovered, as underlined by Renzetti and Petrella (2007), paying particular attention to the traditional cultural heritage, understood as the »combination of lives and lifestyles of the community of men and women " (Renzetti and Petrella 2007, 59), including not only material but also immaterial elements.

In the case-study exposed in the present work, the analysis of the involved areas is realised in parallel with the realisation of a project focusing on the integration of the different capitals: analysis, planning and interaction with the local systems are therefore strictly connected.

\section{Project background: Trentino and the Trentino Ecomuseums Network}

\subsection{The SY_CULTour project in Trentino}

The Organic Production Office of the Province of Trento participates in the SY_CULTour (2011-2014) project, designed to enhance the cultural heritage of peripheral rural areas by seeking synergy with the tourist sector; the project involves a partnership with the Trentino Ecomuseums Network.

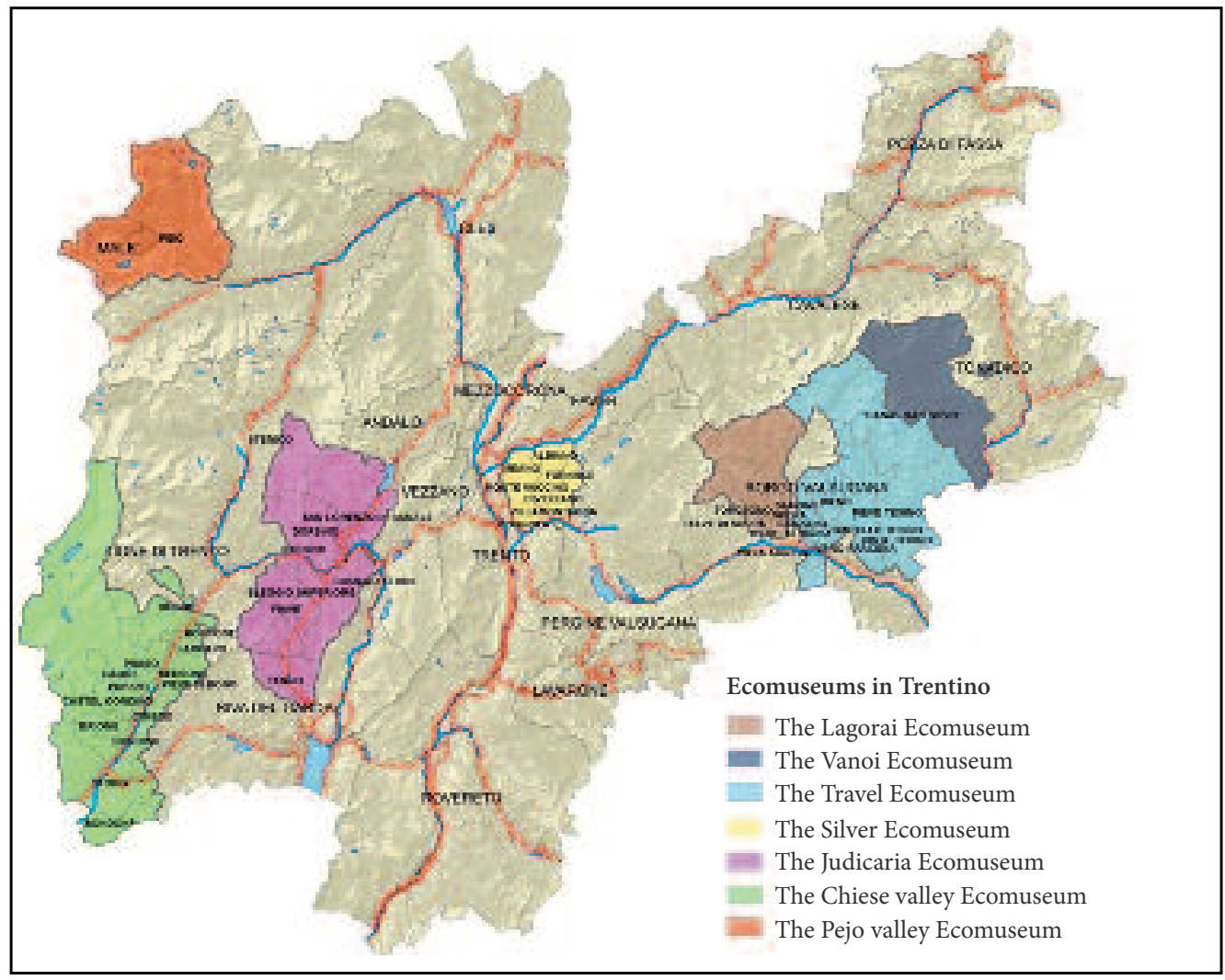

Figure 2: The seven Trentino Ecomuseums. 
In Trentino the focus of the project, called »From tradition to production. The sustainable use of cultivated and spontaneous medicinal plants in the context of rural tourism«, is the use of cultivated and spontaneous medicinal and aromatic plants.

The theme of medicinal and aromatic plants was chosen due to its potential to revitalise declining economies, as it represents a meeting point between different and complementary activities: on the one hand it is a possible area of investment for business activities and on the other it is of interest to associations dedicated to recovering values linked to the rural culture (for more see Bigaran 2008; Bigaran and Visintainer 2009).

The actions developed in the context of the project have the scope of stimulating the creation of thematic tourist packages, mobilising (with a bottom-up approach) the resources of the area and encouraging cooperation between those dealing with the cultivation of medicinal plants and the sustainable gathering of spontaneous plants (supported by the Province through the creation of the Trentinerbe trademark) and the tourist sector (farm guesthouses, wellness centres etc.). The project also aims to promote rediscovery of the traditional cultural heritage of rural communities.

\subsection{Trentino and its ecomuseums}

Trentino is a province in North-East Italy. Covering a surface area of $6,200 \mathrm{~km}^{2}$ and with a population of 525.000 , Trentino lies in the heart of the alpine region. Its territory is entirely mountainous and mostly characterised by natural or semi-natural areas, dominated by forests (56\%), unproductive land (15\%) and pasture (10\%).

Ecomuseums focus on the conservation and enhancement of their area and in particular the indissoluble bond joining an environment to its history, with the people who lived there and still live there. There are currently seven ecomuseums in Trentino (for further information see: http://www.ecomuseums.trentino.it), which are scattered around the province, often situated in the more peripheral and less frequented valleys. In June 2011 they created the Trentino Ecomuseums Network, an informal working and planning instrument set up to encourage relations and the exchange of experience and resources between those involved.

\section{Ecomuseums, farmers and local systems}

\subsection{The SY_CULTour project implementation and the local territorial systems approach}

The territorial capital study in the ecomuseums' areas started with a collection of information and data, obtained by filling two questionnaires: the first one aimed at highlighting the main characteristics of each area and was based on a format created at the international SY_CULTour project level; the second one focused on each area's cultural values; it was based on a format created at the international SY_CULTour project level, whose categories were modified to make them fit each different area.

A »main focus « was identified, capable to catalyse many different cultural values in the ecomuseums' areas and to stimulate not only a development at a local level, but also a synergy between the different pilot actions.

Subsequently, in each of the involved areas the ecomuseums organised meetings with the main actors involved in the cultural values management, integrating the main project vision with the specific local resources and needs: in this way, the already existing territorial capital was enhanced, and at the same time »new « territorial capital was slowly built, being constituted by innovative initiatives capable to enhance the already existing resources. Each action, and the whole project, was structured in a way that the final outputs are a touristic promotion of the cultural values and that self-sufficient initiatives (able to carry on activities without European funds) are created.

\subsection{Seven pilot actions, one project}

As a first step, the ecomuseums involved local stakeholders (administrations, associations, businesses and residents) in considering and formulating synergistic actions on the subject of medicinal plants and their 


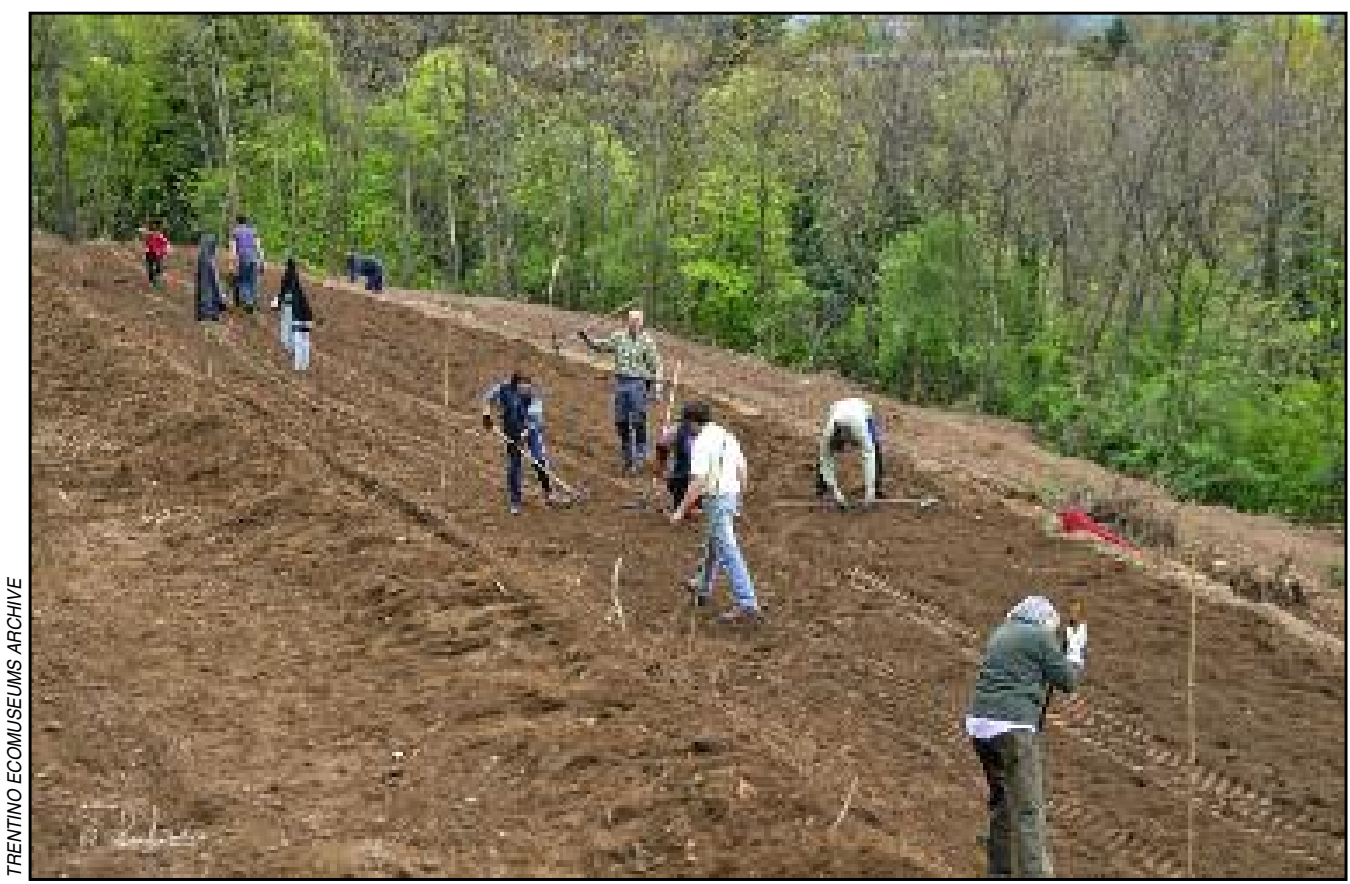

Figure 3: Cooperation between local residents for the creation of a botanical and vegetable garden in Meano (Tn), as part of the SY_CULTour project.

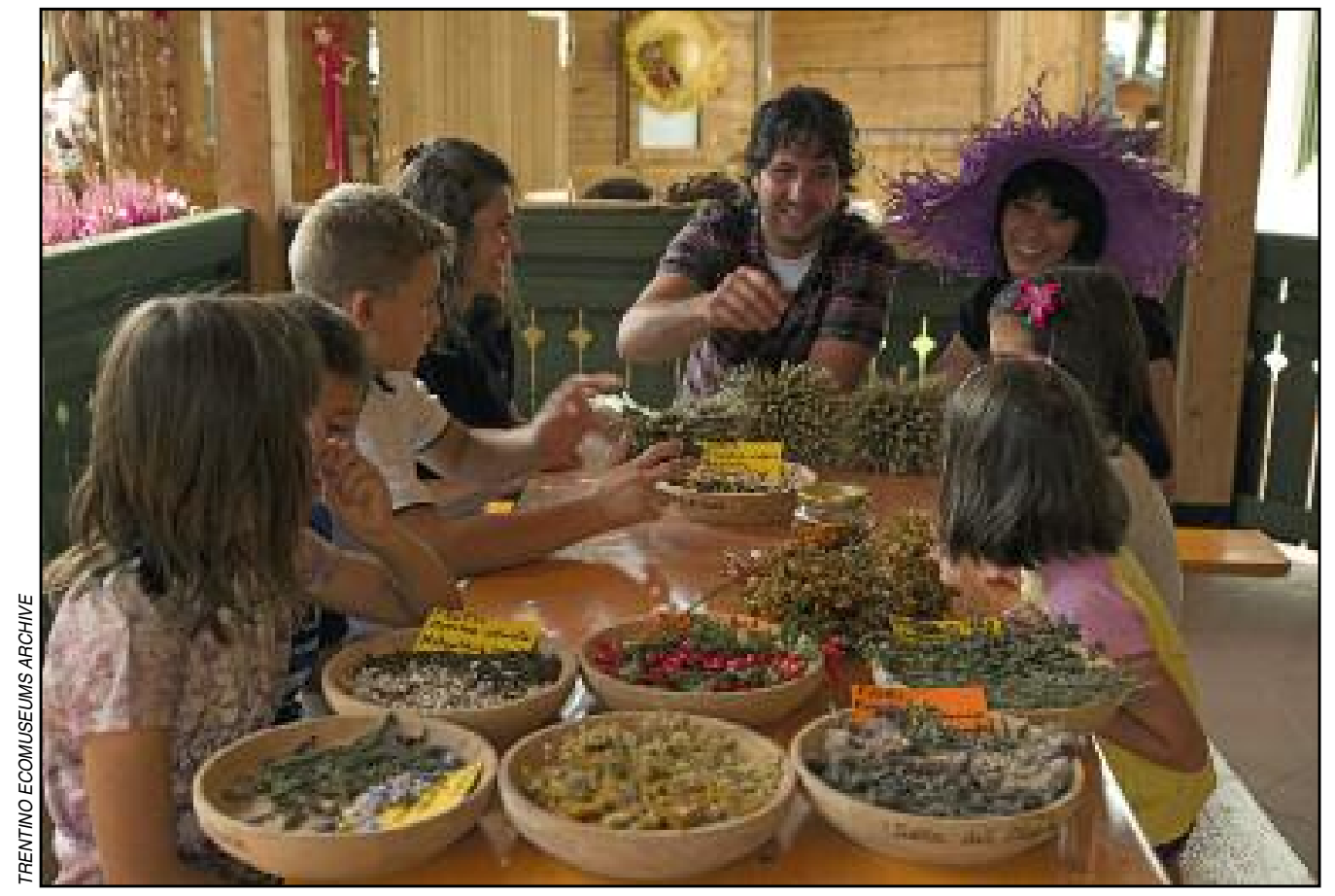

Figure 4: Educational activity on officinal herbs in the Chiese Ecomuseum. 
Table 1: Pilot actions in the ecomuseums (in order to understand the specific characteristics of individual areas each pilot action was given its own title and a specific working plan).

\begin{tabular}{|c|c|c|}
\hline Ecomuseum & Title/main theme & Specific aspects \\
\hline Chiese Ecomuseum & $\begin{array}{l}\text { Kitchen garden remedies - experimental } \\
\text { and educational activities in relation } \\
\text { to the cultivation of medicinal plants } \\
\text { in the Valle del Chiese }\end{array}$ & $\begin{array}{l}\text { Creation of a botanical-medicinal vegetable garden; micro production } \\
\text { chain to market certain products (herb teas and seasonings for } \\
\text { cooking); visits and educational laboratories directed at local } \\
\text { schools and visitors to the ecomuseum. }\end{array}$ \\
\hline Tesino Ecomuseum & $\begin{array}{l}\text { The botanical gardens of Tesino: local } \\
\text { traditions and the use of medicinal } \\
\text { plants }\end{array}$ & $\begin{array}{l}\text { Creation of a botanical vegetable garden in the Tesino Arboretum: } \\
\text { encouraging numerous local farms to rediscover and invest in the } \\
\text { medicinal plant sector; attempt to set up small local production chains. }\end{array}$ \\
\hline Peio Ecomuseum & $\begin{array}{l}\text { The "medicinal gardens" } \\
\text { in the Val di Peio }\end{array}$ & $\begin{array}{l}\text { Starting up of two experimental fields dedicated to the medicinal } \\
\text { varieties present in the area and the cultivation of flax; use of the } \\
\text { products picked to initiate educational laboratories. }\end{array}$ \\
\hline $\begin{array}{l}\text { Argentario } \\
\text { Ecomuseum }\end{array}$ & A vegetable garden in the Villa & $\begin{array}{l}\text { Reclamation and cultivation of an abandoned plot attached to } \\
\text { a prestigious } 1 \text { gh century villa. Cultivation of aromatic and medicinal } \\
\text { plants and vegetables, supporting a small business enterprise run } \\
\text { by young people: guided trips and experiences. }\end{array}$ \\
\hline $\begin{array}{l}\text { Judicaria } \\
\text { Ecomuseum }\end{array}$ & Herbs to experience ... herbs for life & $\begin{array}{l}\text { »Networking« of farms producing medicinal plants, promoting their } \\
\text { specific individual characteristics; expansion of tourist proposals, } \\
\text { offering visitors' routes and accommodation packages adapted to } \\
\text { different needs. }\end{array}$ \\
\hline Vanoi Ecomuseum & Like plants, like the sun & $\begin{array}{l}\text { Raising awareness and involvement of the different groups present in } \\
\text { the valley; creation of gadgets on the theme with the collaboration of } \\
\text { artists, craftsmen and hobbyists; involvement of companies and farm } \\
\text { guest houses in carrying out workshops open to the public; creation } \\
\text { of small kitchen gardens and visitors' routes, in collaboration with } \\
\text { local associations. }\end{array}$ \\
\hline Lagorai Ecomuseum & $\begin{array}{l}\text { Rediscovery of the traditional use } \\
\text { of medicinal plants by the Lagorai } \\
\text { Ecomuseum }\end{array}$ & $\begin{array}{l}\text { Recovery of knowledge and customs linked to medicinal plants } \\
\text { through a survey carried out with the collaboration of primary school } \\
\text { children; use of the survey results to plan informative material and } \\
\text { animate events and excursions directed at the local population locale } \\
\text { and visitors to the ecomuseum. }\end{array}$ \\
\hline
\end{tabular}

traditional uses. By organising public evenings to present the project and meetings with individual organisations, the ecomuseums drew up a series of pilot actions, one per ecomuseum, some of which started up during summer 2012. A number of common activities have also been provided for, designed to create synergy with the actions of individual ecomuseums.

\subsection{Farmers and local systems}

During summer 2012 interviews were carried out with five farmers operating in the areas in which the SY_CULTour project is taking place.

The interviewees, selected between those who were most actively involved in innovative projects related to medicinal and aromatic plants, were asked questions aimed at understanding the background of their activities and reconstructing the networks to which they belong, with the intention of observing the »local systems « in which they are involved and better understanding the prospects for the pilot project.

\section{Farms, innovation, personal development}

All the farmers have come from sectors other than farming, beginning a new business enterprise; they have therefore found it easier to adopt an innovative approach to the management of their farm, as underlined by a farmer from Valsugana: »I come from another world, and perhaps it is not a disadvantage to come from another world because you maybe see things in a different way ; four of them recognise the importance of certification and "guaranteed trademarks«: "Certification undoubtedly represents an extra element, also to reassure the customer that you follow certain rules. (...) Certification is important for controlling farms 
and customer confidence (farmer from the Valli Giudicarie). The Trentinerbe trademark is considered to be a useful tool for "distinguishing « Trentino products, although there are numerous problems, linked mainly to the lack of promotion and dissemination of the trademark.

In all cases, the decision to cultivate medicinal plants was the result of a mixture of personal reasons and the characteristics of the area in which the farm is situated. Indeed all the farms are located in mountainous areas, not particularly suitable for other types of activity: (...) it is hard for us to live in the area. We have a wealth of herbs and plants locally; there is no point doing other things (farmer from the Valle del Chiese).

\section{The cultural background linked to medicinal and aromatic plants}

All the interviewees mention the presence of activities, albeit minor, to gather and cultivate medicinal plants in their family of origin, but above all the existence of a widespread culture linked to the relationship with nature and the countryside: in their grandparents' era all of them picked and used medicinal plants to care for the family and livestock: "(...) they also used plants for the livestock. My grandfather told me that they used to make mixtures for cows giving birth, for example, using plants collected in the meadows to alleviate pain « (farmer from the Valli Giudicarie).

Today the local culture has few links with the pace of the land, although in some areas the virtues of local plants are being rediscovered. The areas in which the farmers operate are all characterised by a thriving natural environment and the widespread custom, at least in the past, of cultivating the land and gathering

Table 2: Main characteristics of the interviewees.

\begin{tabular}{|c|c|c|c|}
\hline Interviewee & Municipality & Ecomuseum & Type of farm/business \\
\hline Female farmer & Roncegno Terme (Valsugana) & Lagorai & Medicinal plants - B\&B \\
\hline $\begin{array}{l}\text { Male farmer } \\
\text { (together with his wife) }\end{array}$ & Roncegno Terme (Valsugana) & Lagorai & Mixed also picking of spontaneous plants \\
\hline Female farmer & Vigo Lomaso (Valli Giudicarie) & Judicaria & Mixed (mostly animal husbandry) \\
\hline Male farmer & Bondone (Valle del Chiese) & Chiese & Mixed also picking of spontaneous plants \\
\hline $\begin{array}{l}\text { Female farme } \\
\text { (together with her husband) }\end{array}$ & Pellizzano (Val di Peio) & Peio & $\begin{array}{l}\text { Medicinal plants for processed products also } \\
\text { picking of spontaneous plants }\end{array}$ \\
\hline
\end{tabular}

\section{Table 3: Central themes for the interviews.}

Description of farm and experience gained

- history of the farm

- reasons for choosing to cultivate medicinal plants

- problems and possible solutions

Family culture

- custom of parents and grandparents gathering or cultivating medicinal plants

Culture of the area

- custom of local people gathering or cultivating medicinal plants

- interest of local people in the subject of medicinal plants

Social networks

- interest of local people in the farmer's activities

- presence of other people interested in medicinal plants

\section{Economic fabric}

- collaboration with other farmers

- collaboration with other businesses

The area, understood as natural form of support

- suitability of the site for the cultivation / gathering of medicinal plants

- influence of the characteristics of the site on the choice to deal with medicinal plants

Institutions

- support of local / provincial authorities

- importance of certification 
its fruits; the interviewees recognise that older people living locally have a good knowledge of the area and the use of spontaneous species, something which the new generations have lost: »(...) some old people (are used to gathering and cultivating medicinal plants, author's note), but very few. Now everyone goes to the chemist. We have handed everything over to the chemist (farmer from the Valle del Chiese).

\section{Relations with other stakeholders}

All the interviewees believed relations with the local social network to be important, although these were not necessarily effectively cultivated and promoted.

All underlined that initially their activities, also due to the innovative aspects represented by the production of medicinal plants, were observed with a certain suspicion and only over time did local people begin to appreciate their work and become interested. "At the beginning they said we were mad. Now they begin to come and ask for products and also to ask us whether we can give their children a job « said the husband of the farmer from the Val di Peio.

\section{Conclusions}

The good results obtained in the first few months of work have also brought to light a series of problems that the ecomuseums are called on to deal with in order to continue with the individual pilot projects. In addition to start-up difficulties, due to the sluggishness of bureaucratic procedures which initially slowed down the projects, the proposal and starting up of innovative actions was often greeted with distrust and reluctance by local people, despite the presence and activities of ecomuseums in their areas for several years. To encourage the starting up of participatory processes, the ecomuseums carried out activities to provide information and raise awareness in the community at various levels, through public meetings and educational visits.

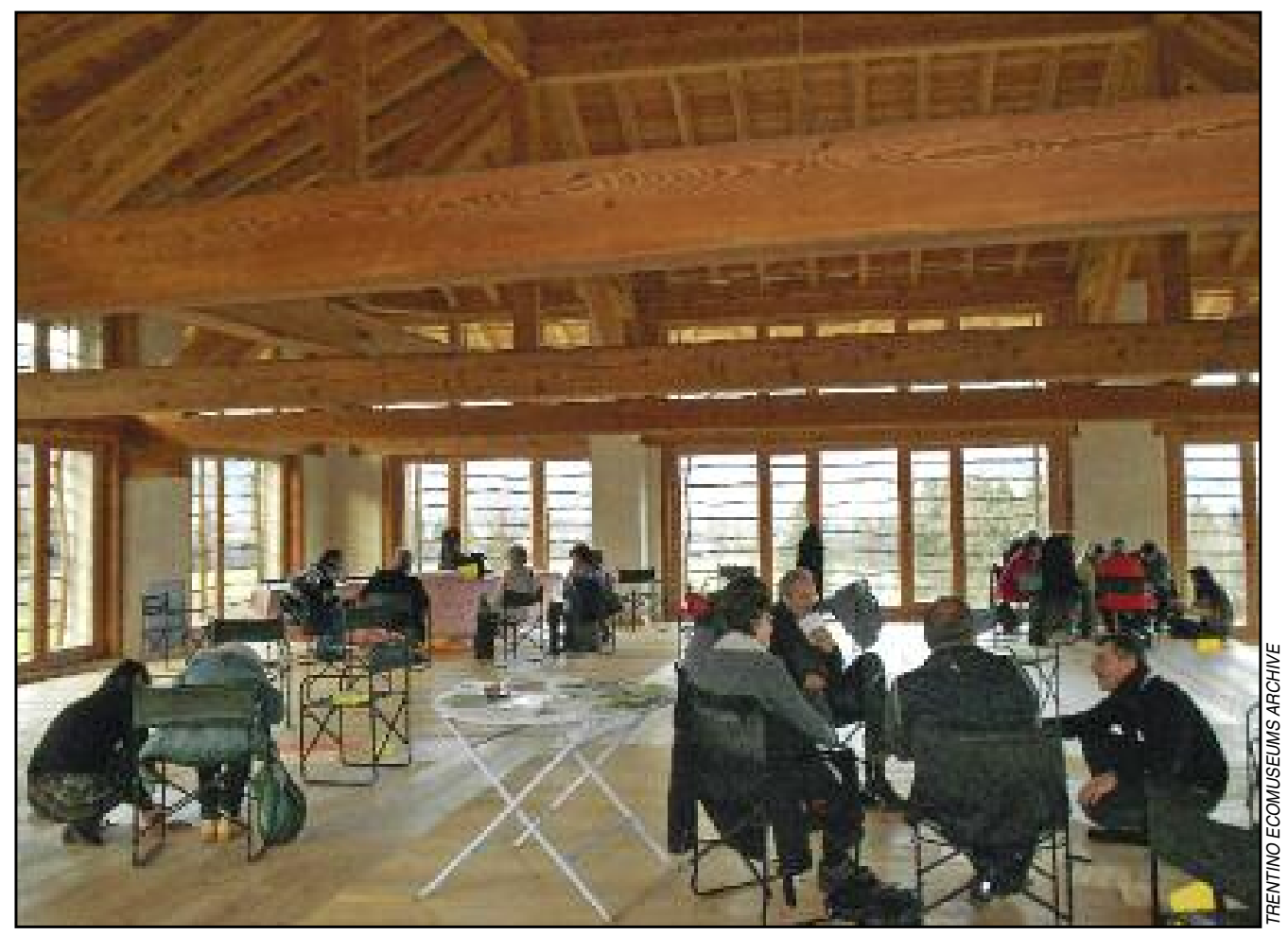

Figure 5: A participative training with the ecomuseums' representatives and local stakeholders. 
Over and beyond the difficulties encountered at the start, all the areas involved in the project have given rise to a considerable wealth of energy and proposals (as also emerged from the interviews carried out), which if appropriately directed, could stimulate the creation of interesting prospects for development, based on local territorial systems.

Naturally, there are many themes around which intervention designed to develop mountain areas could be concentrated; medicinal and aromatic plants are just one of these. They represent a particularly important opportunity - as we have seen - due to their ability to characterise a place of residence and a tourist destination, therefore counteracting depopulation and the decline of marginal areas.

What it is necessary to bear in mind, now as in the future, is that what counts when developing a project with the scope of making the most of local resources is not so much the theme chosen, as the capacity of those involved to use and enhance local resources. It is important not to impose intervention from above which has little to do with the context in which it takes place.

\section{References}

7th European Mountain Convention proceedings. 2010: European Mountain Regions - A spirit of Innovation. Lillehammer.

Bigaran, F. 2008: Promozione e sviluppo del prodotto territoriale, attività di rete con cinque progetti. Europa. 1. Trento.

Bigaran, F., Visintainer, G. 2009: Ritorno alle piante officinali. Terra Trentina 6/2009. Trento.

Bole, D., Nared, J. 2009: The Future of Small Towns in Remote Mountainous Areas: The Alps. City Futures '09 proceedings. Internet: http://www.cityfutures2009.com/PDF/101_Bole_David.pdf (20.12.2012)

Camagni, R. 2007: Towards a concept of territorial capital. 28th Italian conference of regional science proceedings. Bolzano.

Corrado, F. 2007: Il modello SLoT per lo sviluppo locale nelle aree montane. Atti del convegno Autorità locali e attori: generare successo insieme (proceedings). Torino.

Dematteis, G., Governa, F. 2005: Territorialità, sviluppo locale, sostenibilità: il modello SLoT. Milano.

Euromontana. 2011: Services of General Interest in Mountain Areas. Position paper of Euromontana. Brussels.

European Commission. 2003: Green paper on services of general interest. Brussels.

European Commission. 2004: White paper on services of general interest. Brussels.

European Commission. 2007: Services of general interest, including social services of general interest: a new European commitment. Brussels.

European Commission. 2011: Reform of the EU state aid rules on services of general economic interest. Brussels. FairWild. 2010: FairWild Standard 2.0 and previous versions. Weinfelden.

Martial, E., Ottenga, A. 2005: La montagne européenne entre innovation et participation. Une expérience pilote de dialogue entre la demande locale et les stratégies européennes. Milano.

Mazzola, A. 2011: A che svélup ge corone pà dò? Conformismo e dissenso riguardo lo sviluppo turistico. Voci dalla Val di Fassa. Trento.

Renzetti, E., Petrella, A. 2007: Aspetti socio-culturali del patrimonio territoriale in »Attività di rete per lo sviluppo e la promozione dei prodotti territoriali« (proceedings). Gorizia. 